\title{
Chronic Aortic Dissection and Pregnancy: Clinical Case Report
}

Giulia de Miranda Taglialegna, Leila Katz, Larissa Mayara Aristóteles de Albuquerque, Milena Máximo de Freitas, Alexandre Jorge Gomes de Lucena, Melania Maria Ramos de Amorim ${ }^{\bullet}$

Instituto de Medicina Integral Professor Fernando Figueira, Recife, PE - Brazil

\section{Introduction}

Aortic complications during pregnancy can occur in women without risk factors, but they are more often associated with collagen diseases (Marfan and Ehlers-Danlos syndromes) and structural cardiac malformations (aortic coarctation and bivalve aortic valve). ${ }^{1,2}$ Approximately half of these events occur during pregnancy in women under 40 years of age, particularly in the third trimester, or in the postpartum period. ${ }^{3}$ It is an extremely rare event, accounting for $0.1 \%$ to $0.4 \%$ of all aortic dissections, affecting 5.5 (95\% Cl: 4.0 - 7.8) women per 1 million during pregnancy and puerperium. ${ }^{1,4,5}$ It is believed that the physiological hemodynamic changes during pregnancy, structural changes determined by compression of the gravid uterus and the hormonal action can aggravate this aortic pathology. ${ }^{1,6}$

The most commonly used classifications are based on the affected anatomical portion. The Stanford group considers: type A (dissection involving ascending aorta) and type B (descending aorta only). ${ }^{7}$ Depending on the duration of symptoms until the clinical presentation, aortic dissection can be classified as chronic, if it occurs two weeks or more after symptom onset. ${ }^{6}$

We present herein a case of Stanford type B chronic aortic dissection in a patient at the $36^{\text {th }}$ week of pregnancy and discuss the particularities of the diagnosis and management of the potentially severe maternal and fetal complications.

\section{Case Report}

A 35-year-old single pregnant woman, of mixed-race, who had six prior pregnancies with five normal deliveries, at the $36^{\text {th }}$ week of pregnancy, originally from the municipality of Damião, state of Paraíba, Brazil, was referred from Campina Grande, Paraíba, to the intensive care unit (ICU) of IMIP after undergoing an obstetric ultrasonography (USG) that disclosed significant abdominal aorta dilatation. She reported a history of suggestive lancinating abdominal pain approximately one year ago (three months before the diagnosis of pregnancy). She arrived at the Service asymptomatic,

\section{Keywords}

Collagen Diseases/complications; Marfan Syndrome EhlersDanlos Syndrome; Aortic Coarction; Pregnancy; Postpartum Period; Aneurysm, Dissecting/surgery.

\author{
Mailing Address: Giulia de Miranda Taglialegna • \\ Avenida Santos Dumont, 387, apto 402. Postal Code 52050-050, Aflitos, \\ Recife, PE - Brazil \\ E-mail: giuliademiranda@hotmail.com \\ Manuscript received March 08, 2018, revised manuscript June 19, 2018, \\ accepted July 02, 2018
}

DOI: 10.5935/abc.20190044 receiving $\alpha$-Methyldopa $750 \mathrm{mg} /$ day, propranolol $40 \mathrm{mg} /$ day, furosemide $40 \mathrm{mg} /$ day and ASA $100 \mathrm{mg}$ /day.

At the physical examination she was conscious, eupneic, acyanotic, afebrile, with normal skin color, blood pressure (BP) of $100 \times 68 \mathrm{mmHg}$ and heart rate (HR) of 84 beats per minute (bpm). Respiratory auscultation showed no alterations and cardiac auscultation showed regular rhythm, normal heart sounds and no murmurs. She had depressible $++/++++$ edema in the lower limbs; (below the $2.5^{\text {th }}$ percentile for gestational age), physiological tonus, with fetal movements, fetal heart rate of $132 \mathrm{bpm}$ and absence of visceromegaly.

Computed tomography (CT) of the chest and abdomen performed on the first day of hospitalization identified aortic dissection from the aortic arch to the abdominal aorta at the level of the renal arteries (Figures 1 and 2). She underwent an obstetric USG showing a single, live fetus, with estimated weight of $2.316 \mathrm{~g}$, amniotic fluid index of $6 \mathrm{~cm}$, normal umbilical artery Doppler, and gestational age of 35 weeks and 5 days.

She remained asymptomatic until the third day of hospitalization, when she developed lower abdominal pain and uterine dynamics (three contractions in ten minutes), BP of $160 \times 100 \mathrm{mmHg}$ during contractions, and thus, a cesarean section was indicated. The procedure was performed under spinal anesthesia, with the cardiology and vascular surgical teams on alert, without complications, when bilateral tubal ligation was also performed. The newborn was a female, weighing $2.475 \mathrm{~g}$, with an APGAR score of 8/9.

At the postpartum, she was initially followed in the obstetric $\mathrm{ICU}$ and remained stable on propranolol $40 \mathrm{mg} /$ day and amlodipine $5 \mathrm{mg} /$ day, with adequate blood pressure control. She underwent an echocardiogram ( $2^{\text {nd }}$ postoperative day) that showed a $52 \%$ ejection fraction, dissection of the aorta with false-lumen flow, and discrete aortic, mitral and tricuspid regurgitation. The heart chambers showed normal dimensions. On the $5^{\text {th }}$ postoperative day after the cesarean section, she was submitted to a thoracic endoprosthesis implantation without complications. On the $3^{\text {rd }}$ postoperative day after the implantation the patient developed a fever, of which origin was not determined and ceased after the use of vancomycin, piperacillin and tazobactam for 7 days, enoxaparin and prednisone. She was discharged from the $35^{\text {th }}$ postoperative day after the cesarean section and $28^{\text {th }}$ postoperative day after the aortic endoprosthesis implantation, on propranolol $120 \mathrm{mg} /$ day, amlodipine $10 \mathrm{mg} /$ day, losartan $100 \mathrm{mg} /$ day and digoxin $0.125 \mathrm{mg} /$ day and referred to cardiology outpatient follow-up.

\section{Discussion}

Aortic dissection during pregnancy is considered a potentially devastating clinical calamity for mother and conceptus. ${ }^{2}$ Maternal mortality for acute Stanford type A and B dissection corresponds to $21 \%$ and $23 \%$, with fetal death rates of $10.3 \%$ and $35 \%$, respectively. ${ }^{2}$ High rates are related 


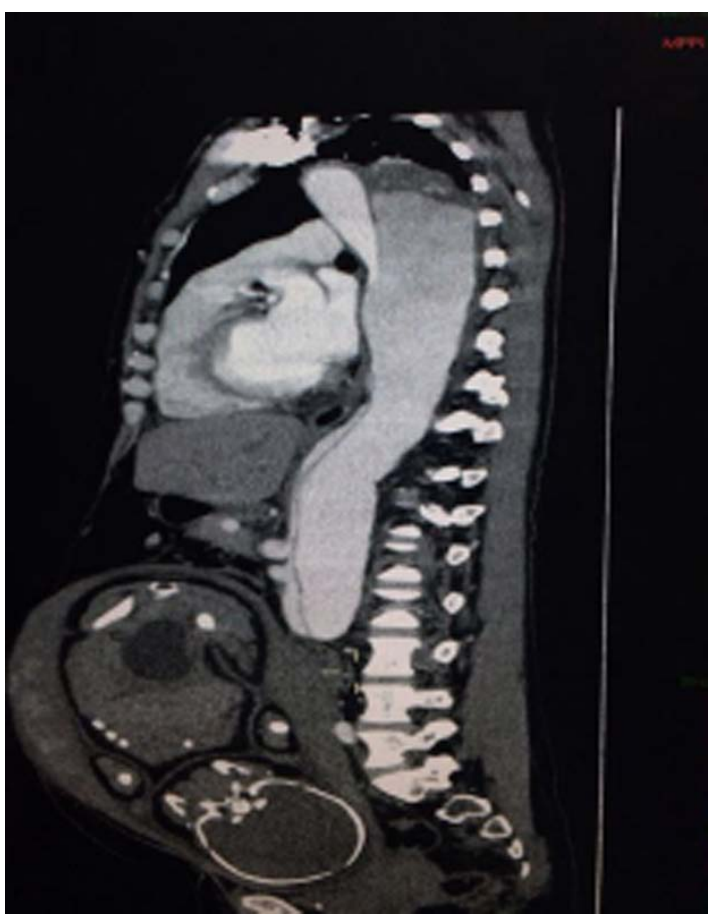

Figure 1 - Computed tomography illustrating type B dissection.

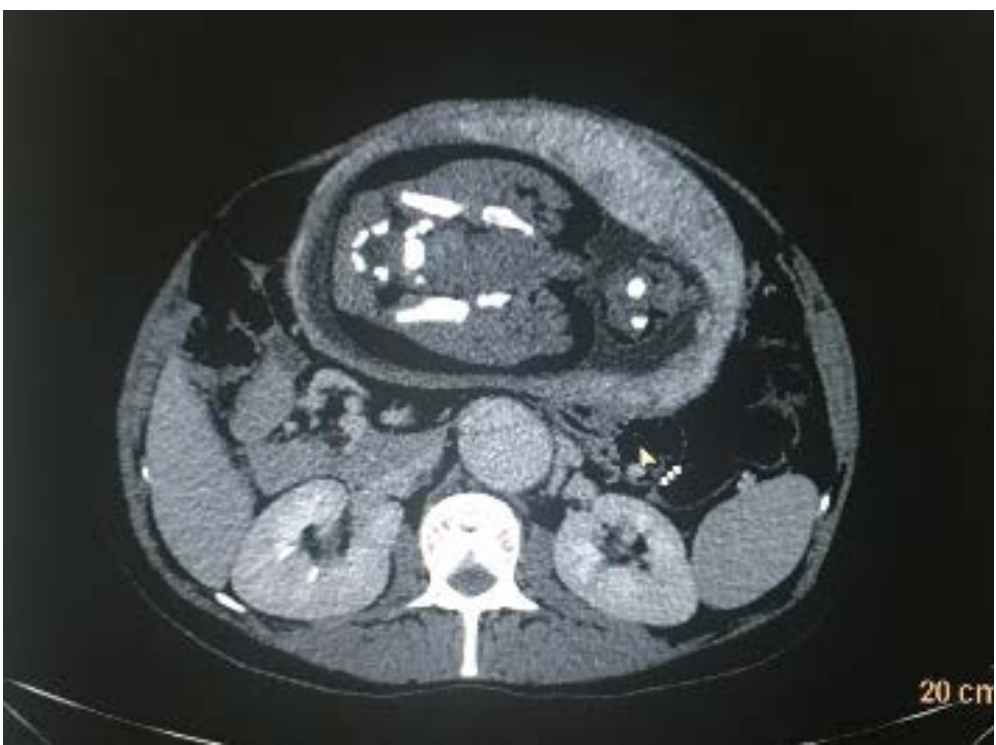

Figure 2 - Computed tomography in axial view showing the dissection extending to the origin of the renal arteries.

to vessel rupture, pericardial tamponade, heart failure, and ischemia of vital organs such as the brain, kidneys, and spinal cord. ${ }^{3}$

When the presentation is acute, the dissection symptoms are typical: sudden onset of thoracic, abdominal, or back pain, of the lancinating type. ${ }^{3}$ The oligosymptomatic picture, such as that presented by the patient, which is typical of chronic dissections, is frequently underestimated and attributed to the physiological changes that occur during pregnancy, causing a delay in the diagnosis. ${ }^{6}$

Despite the known risk of ionizing radiation for the conceptus, it is known that this is small, and in these cases the benefit of performing a CT overcomes the risk. The USG was important initially for the identification of the aortic dilatation. 
The CT allowed the diagnostic confirmation, as well as a better detailing of the dissection extent and involvement of the aortic vascular branches, fundamental data for the dissection classification and therapeutic planning. ${ }^{3}$

The decision about clinical management only or the need for surgical intervention before or after the pregnancy interruption should consider the risk of rupture, type of dissection and fetal viability.

Delamination in the descending aorta characterized the dissection as type $B$ and clinical treatment was chosen during the pregnancy, followed by the implantation of a thoracic endoprosthesis in the immediate postpartum., ${ }^{3,8,9}$ The maternal hemodynamic stability and the strict monitoring of the aortic pathology and fetal vitality allowed this conduct in our service.

Beta-blockers are the first-line drug therapy, as they reduce both HR and BP and, consequently, the shear forces in the aorta, thus limiting the extent of the dissection and reducing the risk of rupture or damage to target-organs. ${ }^{9}$ They can be used with relative safety during pregnancy (Propranolol is a Class C drug by the Food and Drug Administration - FDA). ${ }^{3,8,9}$

The pregnancy interruption prior to the dissection repair offered a greater chance of survival to this conceptus, since the reported rates of morbidity and mortality may reach $30 \%$ and $9 \%$, respectively, during the repair procedures. ${ }^{3,8}$

The type of delivery in patients with heart disease is controversial. A normal delivery results in less bleeding, faster recovery, and decreases the risk of postoperative complications. In the absence of acute dissection, normal delivery can be performed with an aortic diameter $<40 \mathrm{~mm}$ in cases of Marfan Syndrome, with a cesarean section being indicated above this reference value. ${ }^{3,8}$ The carrying out of the delivery should include interventions to reduce aortic wall stress, strict blood pressure control, adequate analgesia, and instrumental delivery when indicated. ${ }^{3,8}$ The patient's aorta had a maximum diameter of approximately five centimeters, which supported the choice of delivery route by the team. Bilateral tubal ligation was appropriately indicated as a definitive contraceptive method and was based on the high risk of maternal death in the event of a new pregnancy. ${ }^{8}$

The great diversity of cases and the small number of cases reported in the literature do not allow establishing guidelines for the management of aortic dissection during pregnancy. Multidisciplinary management and individualized treatment aim to provide survival opportunities for the mother and fetus, considering maternal hemodynamic stability, fetal viability and the best opportunity for surgical intervention, when indicated.

\section{Author contributions}

Conception and design of the research: Taglialegna GM, Katz L, Albuquerque LMA, Freitas MM, Lucena AJG; Acquisition of data: Taglialegna GM, Albuquerque LMA, Freitas MM, Lucena AJG; Analysis and interpretation of the data: Taglialegna GM, Albuquerque LMA, Freitas MM; Writing of the manuscript: Taglialegna GM, Albuquerque LMA, Freitas MM; Critical revision of the manuscript for intellectual content: Katz L, Lucena AJG, Amorim MMR.

\section{Potential Conflict of Interest}

No potential conflict of interest relevant to this article was reported.

\section{Sources of Funding}

There were no external funding sources for this study.

\section{Study Association}

This article is part of the course conclusion of Giulia de Miranda Taglialegna, Milena Máximo de Freitas and Larissa Mayara Aristóteles de Albuquerque from Instituto de Medicina Integral Professor Fernando Figueira.

\section{References}

1. Kamel H, Roman MJ, Pitcher A, Devereux RB. et al. Pregnancy and the risk of aortic dissection or rupture: a Cohort-Crossover Analysis. Circulation. 2016; 134(7):527-33.

2. Sawlani N, Shroff A, Vidovich MI. Aortic dissection and mortality associated with pregnancy in the United States. J Am Coll Cardiol. 2015; 65(15):1600-1.

3. Zhu JM, Ma WG, Peters S, Wang LF, Chiao ZY, Ziganashin BA, et al. Dissection in pregnancy: management strategy and outcomes. Ann Thorac Surg. 2017;103(4):1199-206.

4. Kamalakannan D, Rosman HS, Eagle KA. Acute aortic dissection. Crit Care Clin. 2007;23(4):779-800.

5. Braverman AC, Harris K, Pyeritz R. Aortic dissection during pregnancy: results from the International Registry of Acute Aortic Dissection (IRAD). J Am Coll Cardiol. 2012; 59:E1903.
6. Thrumurthy Sri G, Karthikesalingam Alan, Patterson Benjamin O, Holt Peter J E, Thompson Matt M. The diagnosis and management of aortic dissection BMJ. 2012 Jan 11;344:D8290.

7. Meszaros I, Morocz J, Szlavi J, Schmidt J, Tornoci L, Nagy L, et al. Epidemiology and clinicopathology of aortic dissection. Chest. 2000;117(5):1271-8.

8. Patel PA, Fernando RJ, Augoustides JG, Yoon J, Gutsche JT, Feinman JW, et al. Acute type-B aortic dissection in pregnancy: therapeutic challenges in a multidisciplinary setting. J Cardiothorac Vasc Anesth. 2017;31(6):2268-76.

9. Kaji S. Update on the therapeutic strategy of Type B aortic dissection. J Artherioscler Tromb. 2017;25(3):203-12. 